\title{
Hygroscopic behavior of atmospheric aerosol in Taipei
}

\author{
Lu-Yen Chen ${ }^{\mathrm{a}, *}$, Fu-Tien Jeng ${ }^{\mathrm{a}}$, Chih-Chieh Chen ${ }^{\mathrm{b}}$, Ta-Chih Hsiao ${ }^{\mathrm{c}}$ \\ a Institute of Environmental Engineering, National Taiwan University, 71 Chou-Shan Road, Taipei 106, Taiwan \\ ${ }^{\mathrm{b}}$ Institute of Occupational Medicine and Industrial Hygiene, National Taiwan University, Taiwan \\ ${ }^{\mathrm{c}}$ Department of Civil and Environmental Engineering, Stanford University, USA
}

Received 9 September 2002; received in revised form 20 January 2003; accepted 24 January 2003

\begin{abstract}
Hygroscopic growth of particles of different sizes and the resultant size distribution changes were observed as a function of the relative humidity (RH). A particle generation device, RH module, and a Tandem Differential Mobility Analyzer system were set up to measure the particle size distributions under different RH conditions. Adopting Nafion as an RH adjusting module, the aerosol hygroscopic observations were successfully performed without the interference caused by blending sample stream with humidified air. The measured deliquescence humidity of model compounds, $\mathrm{NaCl}$ and $\left(\mathrm{NH}_{4}\right)_{2} \mathrm{SO}_{4}$, agree with the theoretical values reported by other investigators. The particle growth factor is enhanced around the $\mathrm{RH}$ of $70 \%$. In addition, particle size distribution behaves as two split groups of particles with the $\mathrm{RH}>76 \%$. The average growth factors of hygroscopic ambient particles in Taiwan are similar to those reported elsewhere. There are several hygroscopic salt compositions in ambient aerosols, $\left(\mathrm{NH}_{4}\right)_{2} \mathrm{SO}_{4}$ is the most abundant one. Observed particle deliquescence behaviors showed limited alternation of organics on particle growth at higher RH.

(C) 2003 Elsevier Science Ltd. All rights reserved.
\end{abstract}

Keywords: Hygroscopic growth; TDMA; Aerosol size distribution; Urban aerosol

\section{Introduction}

Aerosol is important in atmospheric processes relating to urban air pollution and climate change (Seinfeld, 1989; Charlson et al., 1992). The hygroscopic behavior significantly influences the size distribution of atmospheric aerosols. The particle growth as a function of relative humidity $(\mathrm{RH})$ has been measured with various methods; each method has some constraints. The continuous-flow apparatus with a particle counter initially used by Tang et al. (1977) was employed to measure the growth of monodisperse particles made of pure and mixed salts (Tang and Munkelwitz, 1977; Tang et al., 1978). They manipulated the RH by blending aerosols with dry nitrogen and humidified air. This sample-diluting and time-consuming process was not suitable for cases with lower particle concentrations and the residence time $<5 \mathrm{~min}$. In addition, the particle

\footnotetext{
*Corresponding author. Fax: + 886-2-23625946.

E-mail address: lychen@airlab.ntu.edu.tw (L.-Y. Chen).
}

counter cannot resolve particle size distribution; thus, polydisperse particles present in ambient air may not be evaluated.

A single-particle levitation device (Tang and Munkelwitz, 1993) was used to measure the deliquescence humidity (DRH) of single dry particles $(6-8 \mu \mathrm{m})$. Recently, the Tandem Differential Mobility Analyzer (TDMA, Rader and McMurry, 1986) with a blending humidifying system has been adopted in both laboratories and fields for measuring size-resolved particle concentrations at different RHs (McMurry and Stolzenburg, 1989; Zhang et al., 1993; Swietlicki et al., 1999).

Several measurements were made to resolve ambient and man-made particle hygroscopy. Pitchford and McMurry (1994) reported the co-existence of morehygroscopic and less-hygroscopic fractions of ambient particles at $\mathrm{RH}>75 \%$, leading to a bimodal growth due to their different water affinity. Cruz and Pandis (2000) generated internally mixed aerosol of inorganic salts and organic acid and compared the deliquescence curves with those from ambient particles. The bimodal 
hygroscopic growth behavior was also observed in England (Swietlicki et al., 1999), with externally mixed ambient particles consisting of three groups of particles. Cocker et al. (2001) observed aerosol size distributions, splitting from a single mode to more modes within 1 day. However, particle growth factors with the limited size distribution and DRH data only provide a partial knowledge in the particle hygroscopic growth process. In this study, the particle size distribution with respect to its hygroscopic history under different RHs was reported to better understand the aerosol growth.

The nature of mixing of ambient particles may vary, dependent upon the aerosol size; the mixed compositions also vary during the water-uptake process associated with higher RH. Hanel and Zankl (1979) concluded that the atmospheric aerosol is mainly internally mixed, whereas McMurry and Stolzenburg (1989) reported externally mixed feature. Time sequences of humidified aerosol (at $89 \% \mathrm{RH}$ ) showed a changing external mixture pattern, or more of more hygroscopic portions may appear at a certain time within a day (Cocker et al., 2001).

In this study, ambient aerosol was measured using a Nafion-based RH adjustment module with the TDMA to provide urban aerosol data in Taipei, Taiwan. The results describe the externally and internally mixed feature of atmospheric particles. The relationship between aerosol composition and the hygroscopic property is evaluated. Based on the size distribution data of dry and grown particles, the influence of the mixture pattern on particle aggregation is discussed.

\section{Experimental setup}

The experimental setup (illustrated in Fig. 1) consists of three major components: a particle generation system, a TDMA system, and an RH adjusting module arranged between the two Differential Mobility Analyzers (DMA1 and DMA2 in Fig. 1). Both atmospheric and laboratory-generated particles were measured. The atmospheric particles and the laboratory-generated aerosol were both fed into the system via the aerosol inlet. DMA1 was used to classify particles. The passing particles remained almost monodisperse. The four classified particle sizes are 53, 82, 95, and $202 \mathrm{~nm}$ in modal mobility diameters. Particles made of well-studied inorganic salts, $\mathrm{NaCl}$ and $\left(\mathrm{NH}_{4}\right)_{2} \mathrm{SO}_{4}$, were used to test the performance of this system.

\subsection{Particle generation system}

Particles were generated with the solution of a pure salt or internally mixed salts by using a constant output atomizer at a given salt concentration $\left(2 \mathrm{gl}^{-1}\right.$ for pure salt and $1 \mathrm{gl}^{-1}$ for each mixed salt). The wet aerosol was dried behind the generator in a diffusion dryer. The particle concentration was adjusted by changing the flow

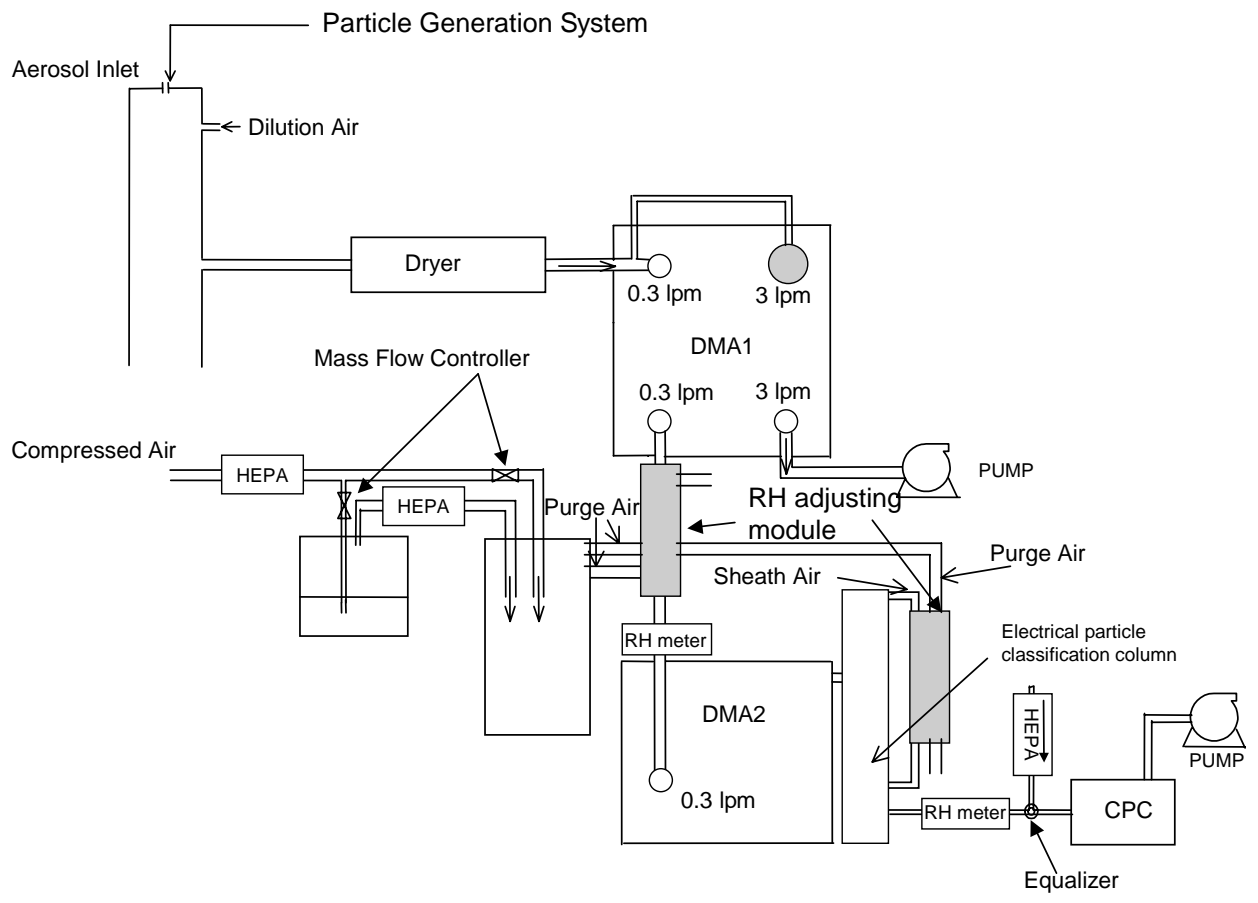

Fig. 1. Experimental setup. 
rate of the dilution air. Particles of internally mixed salts and atmospheric counterparts were compared for their hygroscopic behavior. The RH below $20 \%$ was maintained for both types of aerosols before further size classification in DMA1.

\subsection{TDMA system}

The TDMA system is composed of three parts: (1) the DMA1 (TSI Model 3071A) which allows only "dry" particles within a narrow size range to pass; (2) the DMA2 (TSI Model 3080) which scans the number of "wet" particles in several small size bin; and (3) the Condensation Particle Counter (CPC, TSI Model 3010) which counts the number of DMA-selected particles corresponding to each size bin. The combination of the DMA2 with the CPC forms a Scanning Mobility Particle Sizing system (SMPS, TSI Model 3934) that measures the particle size distribution during the scanning period. The scanning time of the SMPS system was 2 min. The DMA2 adopted in this study is slightly different from the DMA1 model in its air stream design in the electrical particle classification module. A constant RH of the sheath air (model 3080) inside the loop of the electrical particle classification can be maintained; and the results are not affected by the $\mathrm{RH}$ of aerosol flow or exhaust flow. An equalizer is used to maintain the specified flow resistance in this SMPS system.

\subsection{Relative humidity module}

The RH module for controlling and measuring $\mathrm{RH}$ consists of a moisture generator, $\mathrm{RH}$ meters (Rotronic $\mathrm{A} 1 \mathrm{H}$, the precision is $\mathrm{RH} 0.5 \%$ ), and a humidity conditioner. The RH module creates an environment for particles to absorb the moisture and grow; it is expected a complete growth with a long residence time in this study. The RH adjusting module made of Nafion, a sulfonic acid membrane, used by others (Xie and Okada, 1995) was also used in this study. The conditioner chamber needs a lesser time to reach the steady $\mathrm{RH}$, and the Nafion membrane eliminates the particle loss and avoids the pressure equilibrium adjustment (Rupprecht \& Patawshnick, 2000).

In the humidifying process, particles typically need $<10$ s to complete the hygroscopic growth (Ristovski et al., 1998). The particle residence time in one Nafion conditioner is $6 \mathrm{~s}$ at the sample flow rate of $0.31 \mathrm{~min}^{-1}$; for comparison, McMurry and Stolzenburg (1989) used $1.3-5.0 \mathrm{~s}$ in their RH adjustment module. In order to avoid unwanted particle dehydration by the SMPS's "dry" sheath air, the sheath air was humidified by using another Nafion unit to achieve an RH slightly higher than the RH of the aerosol stream fed to the DMA2.
Flow rates of humidified air streams through the Nafion unit were adjusted according to the RH before and after DMA2. In this study, the RH measured after DMA2 is regarded as the $\mathrm{RH}$ of aerosol experienced a complete hygroscopic process. Thus, any dehumidifying and humidifying processes between the DMA2 and CPC will not influence the results of particle counting. The $\mathrm{RH}$ data were recorded by a computer once every $30 \mathrm{~s}$. Both of the two $\mathrm{RH}$ adjusting modules are fed with the moist-saturated air from the same moisture generator; therefore, the ratio of flow rate is adjusted to render the RH difference $<0.5 \%$. The moisture generator is composed of an atomizer, water trap bottles, and high efficiency particulate air filters. The de-ionized water was used to generate the moistsaturated air $\left(15 \sim 301 \mathrm{~min}^{-1}\right)$.

In short, tests with different RHs were handled by continuously blending the saturated air to humidify the initially dried system. In contrast of providing saturated and dry air mixture streams and awaiting for subsequent RH stabilization, this approach made it possible to obtain the particle size distribution information in a much shorter time. A continuous $\mathrm{RH}$-increasing process (from $15 \%$ to $90 \% \mathrm{RH}$ ) can provide particle growth distribution data in $2 \mathrm{~h}$.

\subsection{Chemical analysis}

In addition to the size distribution measured by the TDMA system, another 8-h aerosol samples were collected on Teflon filters by an MOUDI (Micro-Orifice Uniform Deposit Impactor, Model 110, MSP Corp.). Aerosol samples with aerodynamic cut diameters of 56 and $100 \mathrm{~nm}$ were used for further chemical analysis. Soluble ions including $\mathrm{NH}_{4}^{+}, \mathrm{K}^{+}, \mathrm{Ca}^{2+}, \mathrm{Mg}^{2+}, \mathrm{Na}^{+}$, $\mathrm{Cl}^{-}, \mathrm{NO}_{3}^{-}$, and $\mathrm{SO}_{4}^{2-}$ were measured by ion chromatography (Dionex DX-120); the separation columns used in this study were IONPAC-AS4A-SC for cations and IONPAC-CS12A for anions.

\section{Results and discussions}

\subsection{Laboratory-generated aerosol}

The laboratory-generated aerosols made of $\mathrm{NaCl}$ and $\left(\mathrm{NH}_{4}\right)_{2} \mathrm{SO}_{4}$ were used to test the performance of the system. The observed deliquescence data (Fig. 2) are close to the theoretical values (Cruz and Pandis, 2000; Tang, 1980) for RH data greater than DRH. The observed deliquescence curves also agree well with the results reported by other investigators (Tang et al., 1977; Ansari and Pandis, 1999). Specifically, the measure DRHs were $75.6 \pm 0.5 \%$ (9 tests) and $79.6 \pm 0.5 \%$ (7 tests), for $\mathrm{NaCl}$ and $\left(\mathrm{NH}_{4}\right)_{2} \mathrm{SO}_{4}$, respectively. These values are compatible with the respective values of 


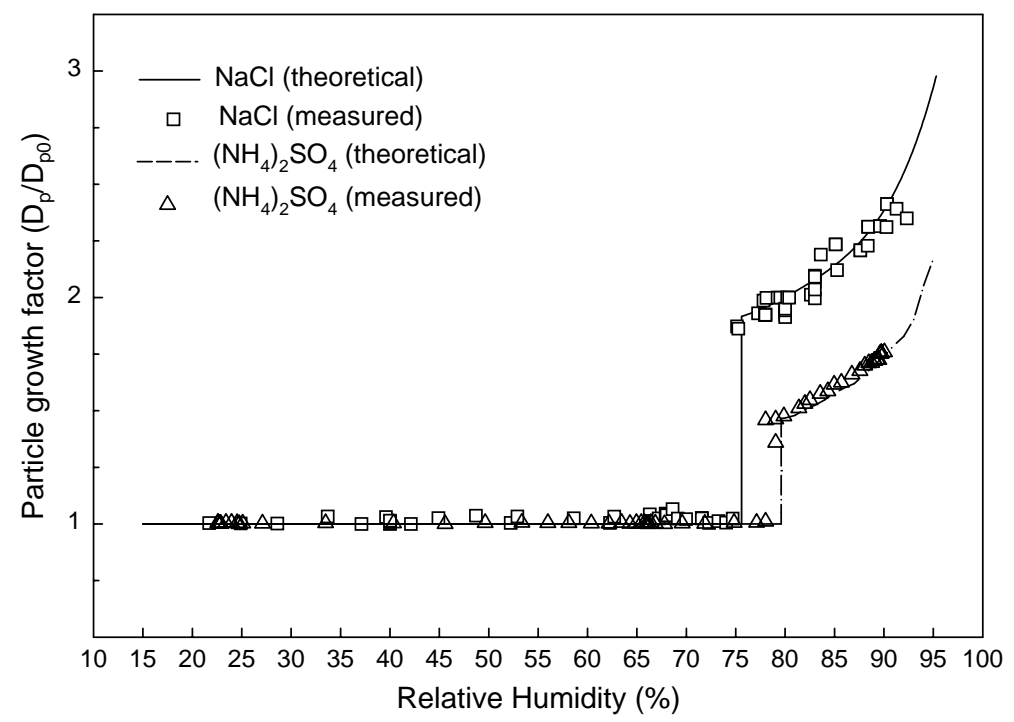

Fig. 2. Deliquescence curves of $\mathrm{NaCl}$ and $\left(\mathrm{NH}_{4}\right)_{2} \mathrm{SO}_{4}$ particles.

$75.7 \pm 0.4 \%$ and $80.0 \pm 0.4 \%$ reported by Tang et al. (1981) as well as $75.0 \pm 1.0 \%$ and $79.0 \pm 1.0 \%$ reported by Cruz and Pandis (2000). The results support that the continuously humidifying process adopted in this study can provide comparable results of test salt particles, and justify the utilization of this approach to monitor the deliquescence process.

\subsection{Atmospheric aerosol}

These data were from the measurements made during the period from 22 October to 31 December 2001. All atmospheric aerosol hygroscopic measurements were made from 13:00 to 15:30 every day. For illustration, observed deliquescence behaviors of one case are shown in Fig. 3. This case was measured on 19 November 2001. During the sampling time, the ambient $\mathrm{RH}$ is about $71 \%$; the ambient temperature is about $21^{\circ} \mathrm{C}$; there was no rainfall. Atmospheric particles of 53, 82, 95, and $202 \mathrm{~nm}$ were classified and fed through the RH adjustment module to the SMPS. To avoid misleading due to particle number differences among different RHs, particle number in each size interval was normalized by the total number for each of RH cases. The variable of vertical axis is the number fraction $\left(N / N_{0}\right)$ distribution with the logarithm of particle diameter $\left(D_{\mathrm{p}}\right)$. The areas under size distribution curves in $\mathrm{d}\left(N / N_{0}\right) / \mathrm{d} \log D_{\mathrm{p}}-D_{\mathrm{p}}$ plane are all unity for each $\mathrm{RH}$ case. The right peak of the size distribution curve with the highest RH is the more hygroscopic fraction, the left peak is the less hygroscopic one. The change of size distribution at different position of RH axis is the water-uptake growth history of tested particles. The splitting growth phenomena during the humidification of atmospheric particles are observed, particularly at high $\mathrm{RH}$ values. Thus, bimodal size distribution at RH near $90 \%$ is the result of the splitting growth phenomena of at least two groups of particles with different hygroscopic behaviors. It has been previously reported that the "split" of particle size distributions at high RH values occurs only for larger particles (say $400-500 \mathrm{~nm}$ ), and it never occurs for smaller size particles (McMurry and Stolzenburg, 1989). In this study, the split growth phenomena were observed for all particle sizes studied, including $53 \mathrm{~nm}$ particles (albeit at much higher RH with a less noticeable phenomenon). However, the difference of shapes among particle size distribution did exist. The splitting growth phenomena typically indicate an externally mixed feature of atmospheric particles, in addition to the internally mixed nature shown by the spreading size distribution peak of humidified particles.

To further illustrate the growth pattern, the growth factor vs. RH is plotted in Fig. 4. There is no obvious particle growth below $45 \% \mathrm{RH}$. In this study, the growth factors are defined as particle's "wet" diameter at $\mathrm{RH}$ around $90 \%$ divided by the "dry" diameter at RH around $45 \%$. As shown in Fig. 4, the particle size distribution began to split into two modes at the RH around $76 \%$. This bimodal growth behavior becomes more noticeable with the increasing RH. The RH at which particle grew dramatically (about $76.4 \%$ for 53 , 82 , and $95 \mathrm{~nm}$, and $77.4 \%$ for $202 \mathrm{~nm}$ in this study) also falls in the range reported by McMurry and Stolzenburg (1989).

Measured growth factors of less hygroscopic portion ranges from 1.11 to 1.17. Growth factors of less hygroscopic particles with dry diameters $<95 \mathrm{~nm}$ were similar. Though the particle diameter resolution was 


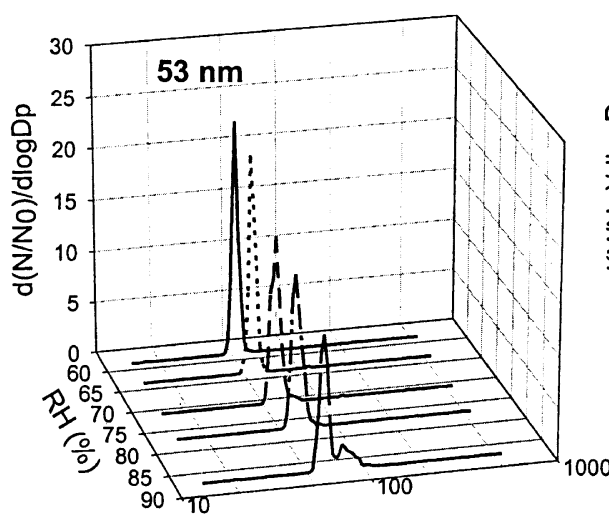

(a)

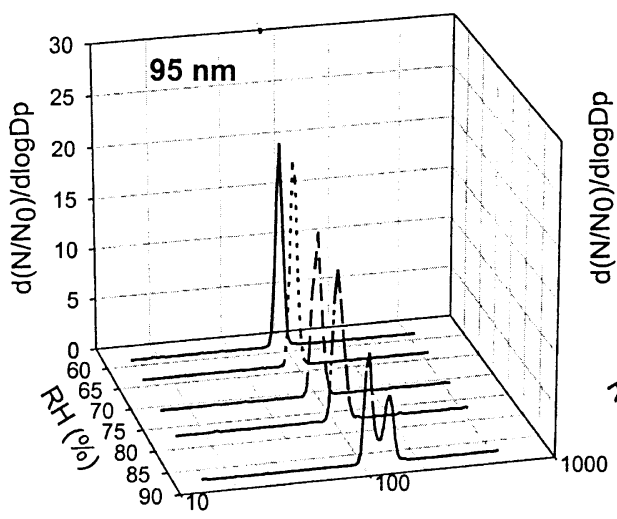

(c)
$\mathrm{Dp}(\mathrm{nm})$

$\mathrm{Dp}(\mathrm{nm})$

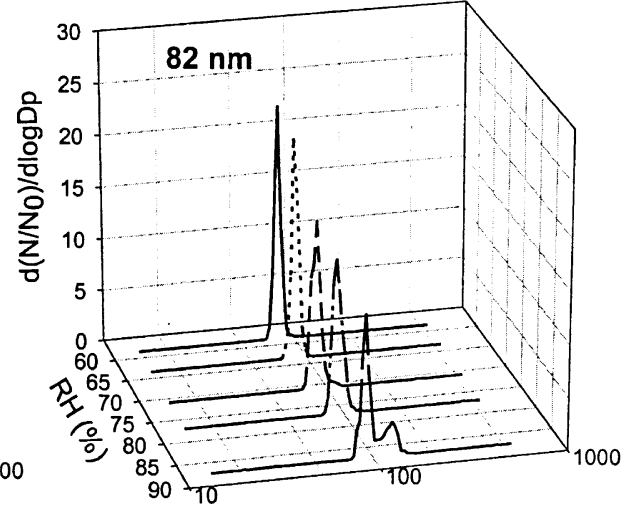

(b)

$D p(n m)$

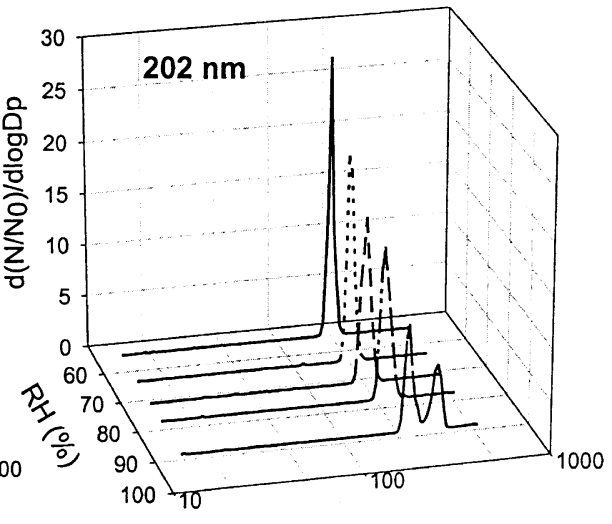

(d)

Fig. 3. Size distributions of atmospheric particles at different RHs. (a) $53 \mathrm{~nm}$, (b) $82 \mathrm{~nm}$, (c) $95 \mathrm{~nm}$, and (d) $202 \mathrm{~nm}$.

limited by the SMPS settings, the results, nevertheless, provide hygroscopic properties of particles with different sizes. In this study, the measured bimodal size distribution began to appear in cases with $\mathrm{RH}$ of $76.4 \%$, $76.5 \%$, and $76.3 \%$ for 53,82 , and $95 \mathrm{~nm}$, respectively. In particular, the results are similar to those reported by Swietlicki et al. (1999) who showed that the average of less hygroscopic particles range from 1.11 to 1.15 corresponding to dry particle diameters of $35-265 \mathrm{~nm}$; those of more hygroscopic particles vary from 1.38 to 1.69 .

The particle size change with RH can be further depicted by the deliquescence curve obtained by drawing the more and less hygroscopic portion separately. As observed in Fig. 4, between the RH from 30\% to $70 \%$ the particles with different size grew by different factors. The growth factor of smaller particles is less than that exhibited by the larger ones. The $\mathrm{RH}$ at which a rapid increase of particle size occurs is around $70 \%$. The observed sudden increases of particle size indicate the presence of internally mixed substances with DRH near RH $70 \%$.
The number distributions of particle of different hygroscopic properties are shown in Table 1. Both growth factors for more and less hygroscopic particles increase with the increase in particle diameters. On the other hand, the number and volume fractions for more hygroscopic particles decrease with the increase in particle diameters. The change of more/less hygroscopic particle ratio with particle size indicates the change of externally salt composition mixed pattern as a function of particle diameter.

Atmospheric particles collected by the MOUDI were used for chemical analysis. These samples were collected from 10:00 to 18:00; this longer sampling time compared with the TDMA measurement was used to get more particles for chemical analysis. The results (shown in Table 1) indicate the presence of $\mathrm{NH}_{4}^{+}, \mathrm{Na}^{+}, \mathrm{K}^{+}$, $\mathrm{Ca}^{2+}, \mathrm{Mg}^{2+}, \mathrm{Cl}^{-}, \mathrm{NO}_{3}^{-}$, and $\mathrm{SO}_{4}^{2-}$ in collected aerosol sample. These data are base on the 48 samples with acceptable ionic balance condition. The aerosol salt composition is reconstructed following the methodology reported by Eldering et al. (1993). The reconstructed salt composition in aerosol includes $\mathrm{NaCl}, \mathrm{KCl},\left(\mathrm{NH}_{4}\right)_{2} \mathrm{SO}_{4}$, 


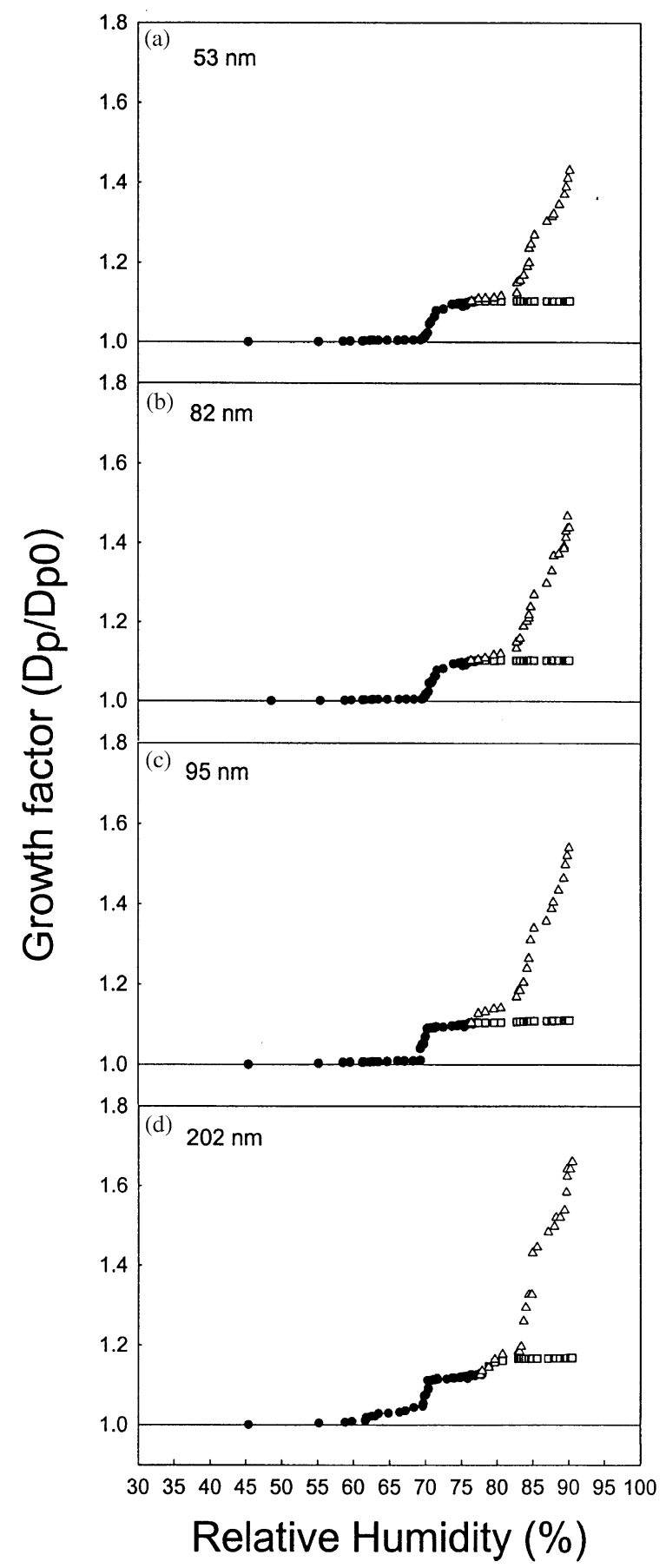

Fig. 4. Observed deliquescence curves of atmospheric particles (95 nm). (a) $53 \mathrm{~nm}$, (b) $82 \mathrm{~nm}$, (c) $95 \mathrm{~nm}$, and (d) $202 \mathrm{~nm}$.

$\mathrm{NH}_{4} \mathrm{NO}_{3}$, and $\mathrm{NH}_{4} \mathrm{HSO}_{4}$, the remaining sulfate is assumed to exist in the other forms. The amount of $\mathrm{NaCl}$ and $\mathrm{KCl}$ is not so much as $\left(\mathrm{NH}_{4}\right)_{2} \mathrm{SO}_{4}, \mathrm{NH}_{4} \mathrm{NO}_{3}$, and $\mathrm{NH}_{4} \mathrm{HSO}_{4}$. It is similar as the composition of single
Table 1

Measured particle number distribution and chemical composition

\begin{tabular}{|c|c|c|c|c|}
\hline \multirow[t]{2}{*}{ Particle properties } & \multicolumn{4}{|c|}{ Dry diameter (nm) } \\
\hline & 53 & 82 & 95 & 202 \\
\hline \multicolumn{5}{|l|}{ Growth factor } \\
\hline Less hygroscopic & 1.11 & 1.11 & 1.11 & 1.16 \\
\hline More hygroscopic & 1.43 & 1.49 & 1.54 & 1.66 \\
\hline \multicolumn{5}{|l|}{ Number fraction $(\%)$} \\
\hline Less hygroscopic & 78 & 74 & 61 & 59 \\
\hline More hygroscopic & 22 & 26 & 39 & 41 \\
\hline \multicolumn{5}{|c|}{ Volume fraction at $90 \% \mathrm{RH}(\%)$} \\
\hline Less hygroscopic & 58 & 52 & 42 & 34 \\
\hline More hygroscopic & 42 & 48 & 58 & 66 \\
\hline \multirow{3}{*}{$\begin{array}{l}\text { Ionic equivalent } \\
\text { conc.(in } \% \text { of total) }\end{array}$} & \multicolumn{4}{|c|}{ Cut diameter (nm) } \\
\hline & \multicolumn{2}{|l|}{56} & \multicolumn{2}{|l|}{100} \\
\hline & Average & S.D. & Average & S.D. \\
\hline $\mathrm{NH}_{4}^{+}$ & 43.0 & 6.7 & 40.5 & 5.3 \\
\hline $\mathrm{Na}^{+}$ & 3.7 & 1.3 & 4.9 & 1.1 \\
\hline $\mathrm{K}^{+}$ & 1.7 & 0.8 & 1.7 & 0.8 \\
\hline $\mathrm{Ca}^{2+}$ & 4.9 & 2.9 & 4.4 & 2.4 \\
\hline $\mathrm{Mg}^{2+}$ & 1.6 & 1.1 & 1.5 & 0.8 \\
\hline $\mathrm{Cl}^{-}$ & 4.8 & 1.8 & 7.1 & 2.2 \\
\hline $\mathrm{NO}_{3}^{-}$ & 11.1 & 7.1 & 10.3 & 6.0 \\
\hline $\mathrm{SO}_{4}^{2-}$ & 29.2 & 7.0 & 29.6 & 7.8 \\
\hline
\end{tabular}

particle with $0.3-0.4 \mu \mathrm{m}$ diameter reported by Guazzotti et al. (2000).

The DRH of $\mathrm{NH}_{4} \mathrm{HSO}_{4}$ is $39 \%$ (Tang, 1980). If there was no substances hindering particles' hygroscopic growth and the $\mathrm{NH}_{4} \mathrm{HSO}_{4}$ amount was significant, the growth should be observed. Since no growth was observed at the $\mathrm{RH}<55 \%$, it is regarded that there was no $\mathrm{NH}_{4} \mathrm{HSO}_{4}$ effective for particle growth at low $\mathrm{RHs}$ in these samples. The $\left(\mathrm{NH}_{4}\right)_{2} \mathrm{SO}_{4}$ was regarded as more abundant composition in these samples. If not hindered by other substances, $\left(\mathrm{NH}_{4}\right)_{2} \mathrm{SO}_{4}$ contributes the particle growth at its $79.5 \%$ DRH (Tang, 1980). However, the composition of $\mathrm{NaCl}, \mathrm{KCl}$, and their internal mixture was much less than $\left(\mathrm{NH}_{4}\right)_{2} \mathrm{SO}_{4}$. Hence, the obvious particle growth at higher RH $(>80 \%)$ should not be contributed by $\mathrm{NaCl}, \mathrm{KCl}$, and their internal mixtures. In this study, besides the water-uptake contribution by $\left(\mathrm{NH}_{4}\right)_{2} \mathrm{SO}_{4}$, no other salt composition was found to contribute particle growth at higher $\mathrm{RH}$. Considering the different influences of organics on particle water uptake reported by Saxena et al. (1995), the net diminishing effect of organics on particle growth should be not significant. 


\section{Conclusion}

In this study, a modified TDMA system was used to measure the hygroscopic behavior of atmospheric aerosols in Taipei. The approach provides a desired RH without blending aerosol samples with humidified air. The results indicate both the internal and external mixture features for particles size ranging from 53 to $202 \mathrm{~nm}$. Moreover, the growth factors of atmospheric aerosols are similar to those reported in other place. The "split growth" phenomenon of atmospheric aerosol was observed for all particle size, e.g., at RH $76 \%$ for $95 \mathrm{~nm}$ aerosol size. The observations suggest that there are several hygroscopic salt compositions in ambient aerosols, $\left(\mathrm{NH}_{4}\right)_{2} \mathrm{SO}_{4}$ is the most abundant one. Observed particle deliquescence behaviors showed limited alternation of organics on particle growth at higher $\mathrm{RH}$. The number distributions of particles with different hygroscopic behaviors also provide further evidence of the externally mixed nature of ambient particles.

\section{Acknowledgements}

This work was carried out with the financial support from the National Science Council of Taiwan (NSC892621-Z-002-059).

\section{References}

Ansari, A.S., Pandis, S.N., 1999. Prediction of multicomponent inorganic atmospheric aerosol behavior. Atmospheric Environment 33, 745-757.

Charlson, R.J., Schwart, S.E., Hles, J.M., Cas, R.D., Coakley Jr., J.A., Hansen, J.E., Hofann, D.J., 1992. Climate forcing by anthropogenic aerosols. Science 255, 423-430.

Cocker, D.R., Whitlock, N.E., Flagan, R.C., Seinfeld, J.H., 2001. Hygroscopic properties of Pasadena, California aerosol. Aerosol Science and Technology 35, 637-647.

Cruz, C.N., Pandis, S.N., 2000. Deliquescence and hygroscopic growth of mixed inorganic - organic atmospheric aerosol. Environmental Science and Technology 34, 4313-4319.

Eldering, A., Larson, S.M., Hall, J.R., Hussey, K.J., Cass, G.R., 1993. Development of an improved image processing based visibility model. Environmental Science and Technology 27, 626-635.

Guazzotti, S.A., Coffee, K.R., Prather, K.A., 2000. Real time monitoring of size-resolved single particle chemistry during INDOEX-IFP. Journal of Aerosol Science 31 (Suppl. 1), S182-S183.

Hanel, G., Zankl, B., 1979. Aerosol size and relative humidity: water uptake by mixtures of salts. Tellus $31,478-486$.
McMurry, P.H., Stolzenburg, M., 1989. On the sensitivity of particle size to relative humidity for Los Angeles aerosols. Atmospheric Environment 23, 497-507.

Pitchford, M.L., McMurry, P.H., 1994. Relationship between measured water vapor growth and chemistry f atmospheric aerosol for Grand Canyon, Arizona, in winter 1990. Atmospheric Environment 28, 827-839.

Rader, D.J., McMurry, P.H., 1986. Application of the tandem differential mobility analyzer to studies of droplet growth or evaporation. Journal of Aerosol Science 17, 771-787.

Ristovski, Z.D., Morawska, L., Hitchins, J., Barron, W., 1998. Influence of the sheath air humidity on the SMPS measurements of hygroscopic aerosols. Journal of Aerosol Science 29, S327.

Rupprecht \& Patawshnick Co., Inc., 2000. Operating ManualSample Equilibrium System with Relative Humidity Module, Albany, NY, pp. 1-2.

Saxena, P., Hildemann, L.M., McMurry, P.H., Seinfeld, J.H., 1995. Organics alter hygroscopic behavior of atmospheric particles. Journal of Geophysical Research 100 (D9), 18755-18770.

Seinfeld, J.H., 1989. Urban air pollution: state of science. Science 243, 745-752.

Swietlicki, E., Zhou, J., Berg, O.H., Martinsson, B.G., Frank, G., Cederfelt, S., Dusek, U., Berner, A., Birmili, W., Wiedensohler, A., Yuskiewicz, B., Bower, K.N., 1999. A closure study of sub-micrometer aerosol particle hygroscopic behavior. Atmospheric Research 50, 205-240.

Tang, I.N., 1980. Deliquescence properties and particle size change of hygroscopic aerosols. In: Willeke, K. (Ed.), Generation of Aerosols. Ann Arbor, Michigan, pp. 153-167 (Chapter 7).

Tang, I.N., Munkelwitz, H.R., 1977. Aerosol growth studiesIII ammonium bisulfate aerosols in a moist atmosphere. Journal of Aerosol Science 8, 321-330.

Tang, I.N., Munkelwitz, H.R., 1993. Composition and temperature dependence of the deliquescence properties of hygroscopic aerosols. Atmospheric Environment 27A, 467-473.

Tang, I.N., Munkelwitz, H.R., Davis, J.G., 1977. Aerosol growth studies-II preparation and growth measurements of monodisperse salt aerosols. Journal of Aerosol Science 8, $149-159$.

Tang, I.N., Munkelwitz, H.R., Davis, J.G., 1978. Aerosol growth studies-IV phase transformation of mixed salt aerosols in a moist atmosphere. Journal of Aerosol Science 9, 505-511.

Tang, I.N., Wong, W.T., Munkelwitz, H.R., 1981. The relative importance of atmospheric sulfates and nitrates in visibility reduction. Atmospheric environment 15, 2463-2471.

Xie, G., Okada, T., 1995. Water transport behavior in Nafion 177 membranes. Journal of the Electrochemistry Society 142, 3057-3062.

Zhang, X.Q., McMurry, H., Hering, S.V., Casuccio, G.S., 1993. Mixing characteristics and water content of submicron aerosols measured in Los Angeles and at the Grand Canyon. Atmospheric Environment 27A, 1593-1607. 